\title{
Experience versus complication rate in third molar surgery
} Waseem Jerjes*1, Mohammed El-Maaytah ${ }^{2}$, Brian Swinson ${ }^{3}$, Bilquis Banu ${ }^{4}$, Tahwinder Upile ${ }^{5}$, Sapna D'Sa ${ }^{6}$, Mohammed Al-Khawalde ${ }^{7}$, Boussad Chaib ${ }^{8}$ and Colin Hopper ${ }^{9}$

\begin{abstract}
Address: ${ }^{1}$ Honorary Lecturer, Department of Oral \& Maxillofacial Surgery, Eastman Dental Institute \& University College London Hospitals, 256 Gray's Inn Road, London WC1X 8LD, UK, 2'Specialist Registrar, Department of Oral and Maxillofacial Surgery, University College London Hospitals, London, UK, ${ }^{3}$ Specialist Registrar, Department of Oral and Maxillofacial Surgery, University College London Hospitals, London, UK, ${ }^{4}$ Specialist in Surgical Dentistry, Department of Oral \& Maxillofacial Surgery, Eastman Dental Institute for Oral Healthcare Sciences, London, UK, ${ }^{5}$ Specialist Registrar, Head \& Neck Surgery Unit, University College London Hospitals, London, UK, ' 5 Specialist Registrar, Department of Oral and Maxillofacial Surgery, University College London Hospitals, London, UK, ${ }^{7}$ Specialist, Department of Oral \& Maxillofacial Surgery, Royal Medical Services, Amman, Jordan, ${ }^{8}$ Reasearcher, Royal Free \& University College Medical School, London, UK and ${ }^{9}$ Head Of Academic Surgical Unit, Senior Lecturer/Consultant Oral \& Maxillofacial Surgeon, Eastman Dental Institute \& University College London Hospitals, London, UK
\end{abstract}

Email: Waseem Jerjes* - waseem_wk1@yahoo.co.uk; Mohammed El-Maaytah - elmaaytah@hotmail.com;

Brian Swinson - brianswinson@totalise.co.uk; Bilquis Banu - bilquisb@hotmail.com; Tahwinder Upile - khawalde@gmail.com; Sapna D'Sa - sapnadsa@ hotmail.co.uk; Mohammed Al-Khawalde - khawalde@gmail.com; Boussad Chaib - boussadc@yahoo.co.uk; Colin Hopper - c.hopper@ucl.ac.uk

* Corresponding author

Published: 25 May 2006

Head \& Face Medicine 2006, 2:14 doi:10.1186/1746-160X-2-14

This article is available from: http://www.head-face-med.com/content/2/1/14

(c) 2006 Jerjes et al; licensee BioMed Central Ltd.
This is an Open Access article distributed under the terms of the Creative Commons Attribution License (http://creativecommons.org/licenses/by/2.0), which permits unrestricted use, distribution, and reproduction in any medium, provided the original work is properly cited.

\begin{abstract}
Objectives: The records of 1087 patients who underwent surgical removal of third molar teeth were prospectively examined to analyse the possible relationship between postoperative complications and the surgeon's experience parameter.

Method and materials: Seven surgeons (three specialists in surgical dentistry [specialists SD] and four oral and maxillofacial Senior House Officers [OMFS residents]) carried out the surgical procedures. For each patient, several variables were recorded including age, gender, radiographic position of extracted teeth, treating surgeon, duration of surgery and postoperative complications.

Results: Analysis of the data revealed some differences in the incidence of complications produced by the specialists SD and OMFS residents. The main statistically relevant differences were increase the incidences of trismus, nerve paraesthesia, alveolar osteitis and infection in the resident-treated group, while the specialist-treated group showed higher rates of post-operative bleeding.
\end{abstract}

Conclusion: The higher rate of postoperative complications in the resident-treated group suggests that at least some of the complications might be related to surgical experience.

Further work needs to compare specialists of training programmes with different years of experience, using large cross - sectional studies. 


\section{Introduction}

Dentoalveolar surgery and especially surgical removal of third molar teeth continues to be the most common surgical procedure performed in the speciality of oral \& maxillofacial surgery.

The surgical removal of third molar teeth may result in a number of complications including pain, swelling, bleeding, alveolar osteitis (dry socket) or nerve dysfunction [1]. The factors that usually contribute to such problems are numerous and include the patient, tooth-related and the surgeon's operative experience [2].

Although careful attention to surgical details, including proper patient preparation, asepsis, meticulous management of hard and soft tissue, controlled force when applying surgical instruments, haemostasis and adequate post operative instructions may help to reduce this rate of complications it has not been proven to eliminated them. Other parameters found to affect the complication rate include age [3], gender [4], and the surgeon's experience $[5,6]$.

Several authorities have suggested the use of antibiotics placed in the alveolar socket to decrease the bacterial plaque and thereby reduce inflammation, pain and trismus [7,8]. Ragno and Szkutnik [9] recommended the use of chlorhexidine mouth rinses prior to the surgical extraction of impacted third molars to reduce postoperative complications. Penarrocha et al. [10] produced evidence that improving the oral hygiene of the patient preoperatively helps to reduce the rate of postoperative complications, most noticeably in pain.

The literature that compares the experience of surgeons to postoperative complications is sparse as it may have implications in the training of junior surgeons [11].

Sisk et al. [6] investigated the effect of the experience of the surgeon on the complication rate following surgical removal of third molar teeth by comparing an oral surgery faculty group to resident group in the same faculty. They showed that complications were numerous after removal of teeth classified as a partially or completely impacted within bone and also that less experienced surgeons had significantly higher incidences of complications.

Handelman et al. [12] carried out a study to assess the postoperative complications in patients who had undergone surgical removal of third molars by OMFS residents and were compared with those of patients whose extractions were performed by general dentistry residents. They showed that there was no significant difference in complication rates between the two groups, but the pain relief requirements, for patients treated by general dentistry res- idents, was shown to be higher. This was shown not related to the level of experience but to the type of analgesics administered following the treatment.

Berge and Gilhuus-Moe [13] compared postoperative complications following surgical removal of third molars in two groups of patients. Surgery was performed on the first group by four general dental practitioners and on the second group by a consultant oral surgeon. An increased rate of postoperative alveolar osteitis, pain and increased duration of surgery was found in the general practitioners group.

de Boer et al. [14] showed higher complication rates following third molar surgery in the hands of residents in alveolar osteitis, swelling and post-operative bleeding. Senior staff in the same study showed higher rates of postoperative infection and paraesthesia.

Generally speaking, inexperience of the surgeon has been shown to relate to increased postoperative complications $[6,13]$. Other studies have, however, failed to reveal any correlation between the experience of the surgeon and postoperative complications [12].

The aim of this study was to compare the incidence of complications following third molar surgery in the hands of a group of surgeons, specialists and residents, to examine whether the experience parameter has a major or minor influence on the results.

\section{Materials and methods}

The records of 1087 patients undergoing surgical removal of third molar teeth were prospectively collected. This included 569 cases in which the removal of third molar teeth in outpatients was performed by three specialists in surgical dentistry in the Department of Oral and Maxillofacial Surgery, Eastman Dental Hospital, London. The prospective records of 518 cases in which the same procedure was performed during the same period by 4 residents (senior house officers) in oral and maxillofacial surgery were also recorded. The cases were analysed to examine incidence of any postoperative complications.

For each patient, the following data was collected:

- Age

- Gender

- Radiographic position (fully erupted, partially impacted or fully impacted)

- Treating surgeon (specialist or resident) 
- Surgical technique (described below)

- Closeness to inferior dental nerve (tooth $\leq 2 \mathrm{~mm}$ is considered to be close)

- Duration of surgery

- Postoperative complications (measured 1 week postoperatively)

1. Inflammation: local reddening and swelling of the area following the surgical insult.

2. Infection: opening a flap and exposing the underlying tissue to various microbes can lead to infection; patients were recorded as having an infection if they presented with severe pain, swelling and inflammation after the initial swelling subsided.

3. Abscess: abscess can be felt clinically by bi-manual palpation; associated signs and symptoms include pain, pyrexia, swelling, inflammation, trismus and pus discharge.

4. Trismus: our protocol defines trismus as a mouth opening (interincisal distance) of $<25 \mathrm{~mm}$ postoperatively.

5. Swelling: very difficult to assess especially in a clinical field; in our study we considered soft tissue swelling as an "obvious facial asymmetry".

6. Bleeding: no patient presented with any haemorrhage, any patient who presented with continuous blood loss from the socket is recorded as have postoperative bleeding.

7. Sore throat: was recorded as a complication in patients who presented with pharyngeal pain and dysphagia and reddening of the area on clinical examination.

8. Alveolar osteitis [dry socket]: was recorded as a complication in patients who presented with dull aching pain in an inflamed tooth socket.

9. Delayed healing: a patient was recorded as having delayed clinical healing when further surgical treatment was required on a postoperative visit (e.g. re-suturing).

10. Temporary and permanent nerve dysfunction: nerve paraesthesia data were either related to the inferior alveolar nerve or the lingual nerve. All patients with paraesthesia were followed up for the first four weeks following surgery, six months and up to two years, with any patient beyond this time being considered to have permanent nerve dysfunction.
11. Pain: the most common postoperative complication following third molar surgery; this complication was not investigated in our study.

All surgical procedures were performed in three similar clinics, equipped with similar surgical instruments, rotary and irrigation devices and materials (sutures and haemostatic agents). Prior to surgery, each patient was informed of possible complications including the possible risk of nerve damage during the procedure and provided fully informed consent.

Local anaesthesia was applied (2\% Lidocaine with 1:100,000 epinephrine) by local tissue infiltration and inferior alveolar nerve block injection, and no more than five cartridges were given to any single patient.

Surgical approach was implemented in all cases. An envelope mucoperiosteal flap was reflected and bone was removed with a round bur in a straight handpiece. Sectioning of the teeth was carried out using a fissure bur. The sectioning in all cases was performed from the root bifurcation area to the occlusal surface; no other sectioning technique was implemented. Bone removal and sectioning of the tooth was performed under continuous irrigation with sterile saline solution at room temperature. The wound was carefully irrigated and any bony spicules removed. The flap was then repositioned and sutured with 4-0 Vicryl. No lingual flap was employed in any of the cases. No patient in this study underwent coronectomy.

Immediately postoperatively all patients were given written instructions about wound care and possible complications in the post-operative period. For all patients, metronidazole (400 mg three times daily for five days) was prescribed as an antimicrobial agent; it is well documented in the literature that metronidazole is the standard medication used following this kind of surgery as it covers most of the spectrum of the microbial infections. Ibuprofen (400 mg three times daily for five days) was prescribed as an analgesic. All patients in this study were reviewed seven days postoperatively.

The cases were distributed among specialists and residents randomly regardless of patient's age, gender or even complexity of surgery. Patients were required to undergo removal of at least one mandibular third molar tooth for inclusion in this study.

No surgical exploration was implemented for any of the patients presented with paraesthesia for less than two years. Patients who continued to have this symptom over two years (permanent) were reviewed to assess their condition and were advised to undergo surgery to explore the 
Table I: Profile of treated cases

\begin{tabular}{lll}
\hline Category & Description & $\mathrm{n}(\%)$ \\
\hline Gender & Male & $501(46.1)$ \\
& Female & $586(53.9)$ \\
Age (years) & Mean & 23.3 \\
& Median & 22.0 \\
& SD & 4.2 \\
Regree of impaction of 3rd molar & Range & $17-36$ \\
& Fully erupted & $104(9.6)$ \\
& Partially erupted & $857(78.8)$ \\
Proximity to inferior alveolar nerve & Fully impacted & $126(11.6)$ \\
& $>2$ mm & $244(22.4)$ \\
Duration of surgery (mins) & $<=2$ mm & $843(77.6)$ \\
& Mean & 18.1 \\
Seniority of surgeon & Median & 18.0 \\
& SD & 7.3 \\
& Range & $4-39$ \\
\hline
\end{tabular}

area that could include undertaking microneurosurgical repair for the appropriate cases.

\section{Statistical methods}

The adverse outcomes from surgery were summarised as frequencies separately according to the grade of the surgeon undertaking the procedure. The Chi-squared statistic was used to test for differences in the case-mix between the surgical grades. The odds ratio (and associated 95\% confidence interval) for each adverse outcome was calculated to compare the likelihood of a patient suffering that outcome between the surgical grades, such that an odds ratio greater than one indicated greater likelihood of complication in resident-treated group, whereas an odds ratio lower than one indicated the converse.

\section{Results}

The 1087 treated patients had a mean age of 23.3 years and there was a slight female predominance (Table 1). The majority of teeth were partially impacted $857 / 1087$ $(78.8 \%)$ and around three quarters 843/1087 (77.6\%) had roots that appeared radiographically to be within or less than $2 \mathrm{~mm}$ from the inferior alveolar nerve. The mean time to complete surgery was 18 minutes. The shortest surgery was completed in 4 minutes and the longest 39 minutes. The specialists treated slightly more patients $569 / 1087$ (52.3\%) than the OMFS residents did.

The OMFS residents treated more female 303/518 (58.3\%) patients than their senior colleagues (Table. 2), while the specialists treated more male patients 286/569 (50.3\%). Both of the surgeons treated almost similar number of fully erupted and partially impacted teeth, although, the specialists were noted to have removed more teeth reported as fully impacted 92/569 (16.2\%). The residents have treated more patients with wisdom teeth reported to be close to the inferior alveolar nerve $415 / 518(80.1 \%)$. Age of patients was normally distributed between the two groups.

Complications in the resident-treated group were slightly higher but statistically insignificant in terms of swelling 62/518 ( $P=0.643)$, sore throat $9 / 518(P=0.117)$, delayed healing $14 / 518(\mathrm{P}=0.129)$ and abscess formation $7 / 518(\mathrm{P}=0.860)$ (Table. 3$)$. A significant statistical difference in complication rate was noticed in trismus $74 /$ $518(\mathrm{P}=0.003)$, dry socket $99 / 518(\mathrm{P}=<0.001)$ and postoperative infection $54 / 518(\mathrm{P}=<0.001)$, and this was more noted in the resident-treated group. Post-operative bleeding (33/569) was the only significant complication $(P=0.020)$ that was reported in the specialist-treated group.

The resident-treated group were more likely to develop inferior dental $(15 / 518)(P=0.012)$ and lingual nerve paraesthesia $(24 / 518)(\mathrm{P}=<0.001)$ within the first two weeks following surgery. This group were also more likely to sustain such a complication $\{$ (lip numbness $P=0.056$ ), (tongue numbness $\mathrm{P}=0.048$ ) $\}$ for the first two years following surgery. 
Table 2: Case-mix in relation to seniority of surgeon

\begin{tabular}{|c|c|c|c|c|c|}
\hline \multirow[t]{2}{*}{ Category } & \multirow[t]{2}{*}{ Description } & \multicolumn{2}{|l|}{ Surgeon } & \multirow[t]{2}{*}{$X^{2}(d f)$} & \multirow[t]{2}{*}{ P-value } \\
\hline & & Resident n (\%) & Specialist n (\%) & & \\
\hline \multirow[t]{2}{*}{ Patient gender } & Male & $2 \mid 5(4 \mid .5)$ & $286(50.3)$ & & \\
\hline & Female & $303(58.5)$ & $283(49.7)$ & $8.37(1)$ & 0.004 \\
\hline \multirow{3}{*}{$\begin{array}{l}\text { Degree of impaction } \\
\text { of } 3^{\text {rd }} \text { molar }\end{array}$} & Fully erupted & $60(11.6)$ & $44(7.7)$ & & \\
\hline & Partially erupted & $424(81.9)$ & $433(76.1)$ & & \\
\hline & Fully impacted & $34(6.6)$ & $92(16.2)$ & $26.92(2)$ & $<0.001$ \\
\hline \multirow{2}{*}{$\begin{array}{l}\text { Proximity to inferior } \\
\text { alveolar nerve }\end{array}$} & $>2 \mathrm{~mm}$ & $103(19.9)$ & $|4|(24.8)$ & & \\
\hline & $<=2 \mathrm{~mm}$ & $415(80.1)$ & $428(75.2)$ & $3.73(1)$ & 0.053 \\
\hline \multirow[t]{4}{*}{ Patient age group } & $17-20$ years & $139(26.8)$ & $156(27.4)$ & & \\
\hline & $21-25$ years & $257(49.6)$ & $273(48.0)$ & & \\
\hline & $26-30$ years & $77(14.9)$ & $75(13.2)$ & & \\
\hline & $31+$ years & $45(8.7)$ & $65(11.4)$ & $2.74(3)$ & 0.434 \\
\hline \multicolumn{2}{|c|}{ Total number of cases treated } & $518(100.0)$ & $569(100.0)$ & & \\
\hline
\end{tabular}

The incidence of any complication is significant when the two treated groups are compared; the benefit was for the specialist-treated group 223/569 (39.2\%).

\section{Discussion}

In general, we found that the Oral and Maxillofacial residents reported a higher incidence of trismus, nerve paraesthesia, alveolar osteitis and infection, while bleeding was the only parameter that showed a higher incidence in the hands of the specialists. The incidence of any complications reached $63.7 \%$ in the resident-treated group and was highly significant $(\mathrm{P}=<0.001)$ when compared to the specialist-treated group. This data was found to be consistent with previous studies ${ }^{6}$.

\section{Trismus and swelling}

Trismus and swelling are subjective findings and difficult to measure objectively, despite being readily observable. Various techniques have been proposed and implemented to measure them $[15,16]$. In this study, trismus and swelling were recorded as complications regardless of their severity. The incidence of trismus was higher in the hands of the residents, which may be related to the effect of prolonged surgery on the masticatory muscles. This was found to be consistent with some studies [4,6,13] and inconsistent with others $[12,14]$. There was no difference between the two groups in terms of swelling. These results are in line with de Boer et al. [14].

Previous studies on the reduction of swelling by administration of dexamethasone have demonstrated a marked effect on the speed of recovery of the patient from the procedure [17]. The administration of antimicrobials was not considered to reduce post-operative trismus and swelling since they are the effect of surgical trauma.

Many surgeons feel that there is no necessity to try to reduce postoperative swelling and trismus as it is a prophylactic phenomenon and usually subsides after 3-5 days in any event.

\section{Wound management}

The incidence of bleeding following third molar extractions was twice as high in the specialist-treated group than in the resident-treated group. These findings are not, however, in line with previous publications $[1,6,14]$.

However, when it comes to infection, OMFS residents' patients are twice as likely to develop infection. This could be related to the fact that those surgeons treated more female patients who have been shown to have an increased tendency to develop infection following surgery.

We found no statistically significant differences in the two groups with respect to delayed healing, sore throat and abscess formation following surgery. These results were inconsistent with previous studies [14].

Usually the administration of antimicrobials, mouthwashes and the maintenance of good oral hygiene have a great effect in preventing or treating such complications to a certain extent. 
Table 3: incidence of each type of post-operative complication in relation to seniority of the surgeon undertaking the procedure.

\begin{tabular}{|c|c|c|c|c|}
\hline \multirow[t]{2}{*}{ Complication } & \multicolumn{2}{|l|}{ Surgeon } & \multirow{2}{*}{$\begin{array}{l}\text { OR }(95 \% \mathrm{Cl}) \\
\text { complication in patient treated by Resident }\end{array}$} & \multirow[t]{2}{*}{ P-value } \\
\hline & Resident n (\%) & Specialist n (\%) & & \\
\hline Trismus & $74(14.3)$ & $49(8.6)$ & $1.77(1.21,2.59)$ & 0.003 \\
\hline Swelling & $62(12.0)$ & $63(11.1)$ & $1.09(0.75,1.59)$ & 0.643 \\
\hline Bleeding & $15(2.9)$ & $33(5.8)$ & $0.48(0.26,0.90)$ & 0.020 \\
\hline Sore throat & $9(1.7)$ & $4(0.7)$ & $2.50(0.76,8.16)$ & 0.117 \\
\hline Dry socket & $99(19.1)$ & $39(6.9)$ & $3.21(2.17,4.75)$ & $<0.001$ \\
\hline Delayed healing & $14(2.7)$ & $8(1.4)$ & $1.95(0.8 \mathrm{I}, 4.68)$ & 0.129 \\
\hline Abscess & $7(1.4)$ & $7(1.2)$ & $1.10(0.38,3.16)$ & 0.860 \\
\hline Infection & $54(10.4)$ & $25(4.4)$ & $2.53(1.55,4.13)$ & $<0.001$ \\
\hline Lip numbness at 2 weeks & $15(2.9)$ & $4(0.7)$ & 4.21 (1.39, I2.77) & 0.012 \\
\hline Tongue numbness at 2 weeks & $24(4.6)$ & $6(1.1)$ & $4.56(1.85,11.24)$ & $<0.001$ \\
\hline Lip numbness at 2 years & $7(1.4)$ & $\mathrm{I}(0.2)$ & $7.78(0.95,63.46)$ & 0.056 \\
\hline Tongue numbness at 2 years & $9(1.7)$ & $2(0.4)$ & $5.01(1.08,23.31)$ & 0.048 \\
\hline Any complication & $330(63.7)$ & $223(39.2)$ & $2.72(2.13,3.48)$ & $<0.001$ \\
\hline
\end{tabular}

\section{Nerve injury}

Previous studies have shown the incidence of damage to the lingual nerve following mandibular third molar surgery varied from $0 \%[18]$ to $23 \%$ [19] and that of the inferior alveolar nerve from $0.4 \%$ [6] to $8.4 \%$ [20]. The incidences of temporary nerve paraesthesia and permanent nerve dysfunction in our study are in keeping with these studies, irrespective of the surgeon's grade.

The OMFS residents reported higher incidence of lingual nerve paraesthesia than their specialist colleagues during the follow-up period. Permanent nerve dysfunction was considered to have occurred two years following surgery and our results show that the resident-treated group were four times more likely to develop this complication. Previous studies have shown that such an incidence may relate to the surgeon's experience, improper use of forceps and poor instrument handling [21].

The resident-group treated slightly higher numbers of patients whose impacted third molar teeth were considered to be close to the inferior dental nerve. This may explain the higher incidence of permanent inferior dental nerve injury in our resident-treated group. They were found to be seven times more likely to induce this complication when compared to the resident-group. The incidence of the permanent damage of the inferior dental and lingual nerves were found to be lower than the incidences reported by Bataineb [22] for both the senior and junior staff and quiet consistent with the results of Sisk et al. [6] for the specialists; while the residents had a lower incidence rate.
If the numbness persists by the end of the monitoring period ( $6 \mathrm{~m}-2 \mathrm{y})$, a further radiograph is required to assess the continuity of the mandibular canal (in case of the inferior dental nerve), and surgical exploration and decompression or repair of the nerve is considered; while, regarding the lingual nerve, surgical exploration is required to check the continuity of the nerve - if the nerve is not intact, a microsurgical repair is required [23].

\section{Dry socket}

The OMFS resident-treated group were found to be three times more likely to develop alveolar osteitis. They, however, had a higher proportion of female patients (58.5\%) who are more susceptible to this complication [24]. The incidence of dry socket also shows marked increase in smokers or patients taking oral contraceptives [24] following surgical removal of third molars. Previous studies had shown that females in general, and especially those taking oral contraceptives are more likely to get alveolar osteitis, which is thought may be due to the estrogenic effect on blood coagulation, which can lead to an early fibrinolysis of the blood clot in the extraction socket [25].

Other factors possibly involved include age, medical status, tooth position, surgical technique, duration of surgery and skills. These results are similarly consistent with other studies $[6,14]$.

Unfortunately, there is no successful method of preventing dry socket, but the incidence of this unpleasant complication can be reduced by employing a number of prophylactic measures, that include: avoiding unnecessary trauma or excessive force during surgery, careful debriding of the socket from any loose fragments, adequate 
postoperative instructions and advice to avoid smoking for at least $24 \mathrm{hrs}$ following surgery.

\section{Conclusion}

The higher rate of postoperative complications in the residents group suggests that at least some of the complications might be related to surgical experience. This raises a number of important issues related to training. Ideally, third molar removal should only be carried out by experienced practitioners and not by occasional surgeons, however, surgeons are not created by divine right and need training to gain the requisite level of experience. This will unfortunately result in a higher level of complications even when residents are closely supervised. Patients have the right to know who will be performing their surgery and might be unhappy with the increased risk of being treated by a trainee.

Further work needs to compare specialists of training programmes with different years of experience, using large cross - sectional studies.

\section{References}

I. Benediktsdottir IS, Wenzel A, Petersen JK, Hintze H: Mandibular third molar removal: risk indicators for extended operation time, postoperative pain, and complications. Oral Surg Oral Med Oral Pathol Oral Radiol Endod 2004, 97:438-446.

2. Berge TI, Boe OE: Predictor evaluation of postoperative morbidity after surgical removal of mandibular third molars. Acta Odontol Scand 1994, 52:162-169.

3. Bruce RA, Frederickson GC, Small GS: Age of patients and morbidity associated with mandibular third molar surgery. J Am Dent Assoc 1980, 101:240-245.

4. Capuzzi P, Montebugnoli L, Vaccaro MA: Extraction of impacted third molars. A longitudinal prospective study on factors that affect postoperative recovery. Oral Surg Oral Med Oral Pathol 1994, 77:34I-343.

5. Shepherd JP, Brickley M: Activity analysis: measurement of the effectiveness of surgical training and operative technique. Ann R Coll Surg Engl 1992, 74:417-420. discussion 42I

6. Sisk AL, Hammer WB, Shelton DW, Joy ED Jr: Complications following removal of impacted third molars: the role of the experience of the surgeon. J Oral Maxillofac Surg 1986, 44:855-859.

7. Olech $E$ : Value of implantation of certain chemotherapeutic agents in sockets of impacted lower third molars. J Am Dent Assoc 1953, 46:154-159.

8. Verbic RL: Local implantation of aureomycin in extraction wounds: a preliminary study. J Am Dent Assoc 1953, 46: 160-163.

9. Ragno JR Jr, Szkutnik AJ: Evaluation of $0.12 \%$ chlorhexidine rinse on the prevention of alveolar osteitis. Oral Surg Oral Med Oral Pathol I99I, 72:524-526.

10. Penarrocha M, Sanchis JM, Saez U, Gay C, Bagan JV: Oral hygiene and postoperative pain after mandibular third molar surgery. Oral Surg Oral Med Oral Pathol Oral Radiol Endod 200I, 92:260-264.

II. Mufson RA: The influence of experience on complication rates. J Oral Maxillofac Surg 1987, 45:906.

12. Handelman SL, Black PM, Desjardins P, Gatlin L, Simmons L: Removal of impacted third molars by oral/maxillofacial surgery and general dentistry residents. Spec Care Dentist 1993, 13:122-126.

13. Berge TI, Gilhuus-Moe OT: Per- and post-operative variables of mandibular third-molar surgery by four general practitioners and one oral surgeon. Acta Odontol Scand 1993, 5I:389-397.

14. de Boer MP, Raghoebar GM, Stegenga B, Schoen PJ, Boering G: Complications after mandibular third molar extraction. Quintessence Int 1995, 26:779-784.
15. Breytenbach HS: Objective measurement of post-operative swelling. Int J Oral Surg 1978, 7:386-392.

16. Norholt SE, Aagaard E, Svensson P, Sindet-Pedersen S: Evaluation of trismus, bite force, and pressure algometry after third molar surgery: a placebo-controlled study of ibuprofen. J Oral Maxillofac Surg 1998, 56:420-7.

17. Baxendale BR, Vater M, Lavery KM: Dexamethasone reduces pain and swelling following extraction of third molar teeth. Anaesthesia 1993, 48:961-964.

18. Chiapasco M, De Cicco L, Marrone G: Side effects and complications associated with third molar surgery. Oral Surg Oral Med Oral Pathol 1993, 76:412-420.

19. Middlehurst RJ, Barker GR, Rood JP: Postoperative morbidity with mandibular third molar surgery: a comparison of two techniques. J Oral Maxillofac Surg 1988, 46:474-476.

20. Lopes V, Mumenya R, Feinmann C, Harris M: Third molar surgery: an audit of the indications for surgery, post-operative complaints and patient satisfaction. Br J Oral Maxillofac Surg 1995, 33:33-35.

21. Mason DA: Lingual nerve damage following lower third molar surgery. Int J Oral Maxillofac Surg 1988, 17:290-294.

22. Bataineh $A B$ : Sensory nerve impairment following mandibular third molar surgery. J Oral Maxillofac Surg 2001, 59:1012-1017. discussion 1017

23. Mozsary PG, Middleton RA: Microsurgical reconstruction of the lingual nerve. J Oral Maxillofac Surg 1984, 42:415-420.

24. Field EA, Speechley JA, Rotter E, Scott J: Dry socket incidence compared after a 12 year interval. Br J Oral Maxillofac Surg 1985, 23:419-427.

25. Muhonen A, Venta I, Ylipaavalniemi P: Factors predisposing to postoperative complications related to wisdom tooth surgery among university students. J Am Coll Health 1997, 46:39-42.
Publish with Biomed Central and every scientist can read your work free of charge

"BioMed Central will be the most significant development for disseminating the results of biomedical research in our lifetime. "

Sir Paul Nurse, Cancer Research UK

Your research papers will be:

- available free of charge to the entire biomedical community

- peer reviewed and published immediately upon acceptance

- cited in PubMed and archived on PubMed Central

- yours - you keep the copyright

Submit your manuscript here:

http://www.biomedcentral.com/info/publishing_adv.asp
BiolMedcentral 